\title{
Effect of type 2 diabetes on the dynamic response characteristics of leg vascular conductance during exercise
}

\author{
Oscar MacAnaney', Heather Reilly', Donal O'Shea², \\ Mikel Egaña' and Simon Green ${ }^{3}$
}

\begin{abstract}
In this study we tested the hypothesis that type 2 diabetes impairs the dynamic response of leg vascular conductance (LVC) during exercise. LVC (leg blood flow/mean arterial pressure) responses were studied during intermittent contractions of the calf muscle in subjects with type 2 diabetes $(n=9)$, heavy controls $(n=10)$ and lean controls $(n=8)$ using a biexponential function and an estimate of the mean response time (MRT). The time constant of the second phase of LVC was significantly greater in type 2 diabetes $(66.4 \pm 29.2 \mathrm{~s})$ than the heavy $(22.2 \pm 13.4 \mathrm{~s})$ and lean (2I.8 $\pm 9.3 \mathrm{~s})$ controls, resulting in a significantly greater MRT in the diabetic group (median [IQR] = 30.7 [24.6-46.5] s versus I6.3 [4.3-23.2] $\mathrm{s}$ and 18.4 [13.7-19.3] s). These data support the hypothesis and suggest that a slowed hyperaemic response in the exercising limb might contribute to exercise intolerance in diabetic subjects.
\end{abstract}

\section{Keywords}

Control, diabetes mellitus, exercise, hyperaemia, muscle

\section{Introduction}

Exercise intolerance is a major complication of type 2 diabetes $^{1-4}$ that is associated with increased mortality. ${ }^{5}$ Although the aetiology of exercise intolerance in type 2 diabetes is not well understood, both a reduction in peak $\mathrm{O}_{2}$ uptake $\left(\dot{V}_{2}\right)^{1-4}$ and a profound slowing of the dynamic response of $\dot{V}_{2}$ during submaximal exercise ${ }^{3,6}$ have been observed in patients with type 2 diabetes. These data are consistent with the exaggerated fall in muscle $\mathrm{PCr}$ and $\mathrm{pH}$ during calf exercise in type 2 diabetes, ${ }^{7}$ suggesting that mechanisms underlying the control of $\dot{V}_{\mathrm{O}_{2}}$ are impaired in this disease.

The control of the dynamic response of $\dot{V}_{\mathrm{O}_{2}}$ during exercise is considered important to the process of fatigue and tolerance of exercise. ${ }^{8}$ The control of $\dot{V}_{\mathrm{O}_{2}}$ depends, to some extent, on the control of $\mathrm{O}_{2}$ delivery and muscle blood flow. ${ }^{9,10}$ Recent evidence of a lower muscle blood flow during steady-state, submaximal exercise ${ }^{2,11}$ raises the possibility that the dynamic control of muscle blood flow is impaired in type 2 diabetes. This would help explain both the larger rise in the NIRS-derived deoxygenated haemoglobin in contracting muscle observed in type 2 diabetes $^{6}$ and the faster decline in 'microvascular $\mathrm{PO}_{2}$ ' during twitch contractions in the streptozotocin-induced diabetic rat. ${ }^{12}$ However, steady-state measures of limb blood flow shed little light on the dynamic response prior to these measurements, ${ }^{13}$ and it is not known if the dynamic response characteristics ${ }^{14}$ of muscle blood flow are altered in type 2 diabetes.

Systems control principles and assessment of dynamic response characteristics have been used to explore the control of ventilation and $\dot{V}_{2}$ during exercise for at least three decades, ${ }^{14-16}$ but their application to the study of the control of blood flow in human skeletal muscle is much more limited. ${ }^{13,17}$ We have adapted venous occlusion plethysmography to the assessment of dynamic response characteristics of leg blood flow in the contracting calf, ${ }^{18}$ an important model of exercise in the study of peripheral vascular disease. ${ }^{19}$ Since this hyperaemic response is linked closely to the control of vasodilation and, thus vascular conductance in contracting skeletal muscle, we used this approach to test the hypothesis that type 2 diabetes impairs the dynamic response of leg vascular conductance during exercise.

\footnotetext{
'Department of Physiology, Trinity College Dublin, Dublin, Ireland 'Department of Endocrinology, St Columcille's and St Vincent's Hospitals, Dublin, Ireland

${ }^{3}$ Department of Physiology, University of Otago, Dunedin, New Zealand
}

\section{Corresponding author:}

Simon Green PhD, Department of Physiology, Otago School of Medical Sciences, University of Otago, Dunedin, New Zealand.

Email: simon.green@otago.ac.nz 


\section{Methods Subjects}

Nine women with type 2 diabetes, 10 overweight but otherwise healthy women ('heavy controls') and 8 lean and healthy women ('lean controls') volunteered to participate in this study. Healthy subjects were recruited from Trinity College Dublin and diabetic subjects were recruited from the Diabetes Unit at St Colmcilles Hospital, Dublin. Exclusion criteria for participation in this study included (1) a diagnosis of peripheral arterial disease (ankle:brachial pressure index $<0.9$ ), hypertension (systolic blood pressure $>140 \mathrm{mmHg}$ ), coronary heart disease (described in the following), neuropathy or retinopathy, (2) were smokers or had smoked during the 12-month period preceding the study or (3) were taking insulin, beta-blockers, calcium channel blockers or any other antihypertensive drugs. All diabetic subjects had a clinical history of diabetes that ranged between 1 and 4 years; but immediately prior to the study did not have clinical evidence of ischaemic heart disease (normal ECG during treadmill stress test) or renal and hepatic dysfunction (urinary protein $<200 \mathrm{mg} \mathrm{dl}^{-1}$; urinary creatinine levels $<2.2 \mathrm{mg} \mathrm{dl}^{-1}$ ).

Physical characteristics of the subjects are shown in Table 1. Prior to and during this study the diabetic subjects were taking either metformin $(n=5)$, avandmen $(n=1)$, statins $(n=3)$ and/or an angiotensin-converting enzyme (ACE) inhibitor $(n=1)$. None of the subjects were taking contraceptive drugs during this period. Subjects were both premenopausal ( $n=11: 4$ diabetic, 4 heavy and 3 lean) and postmenopausal ( $n=16: 5$ diabetic, 6 overweight and 5 lean) whose ages ranged between 34 and 69 years. All premenopausal subjects were tested during days $7-10$ of their menstrual cycle. Subjects were classified as sedentary ( $\leq 1$ hour week ${ }^{-1}$ of moderate intensity exercise in the preceding 3 months), which was confirmed using the Low Level Physical Activity Recall (LOPAR) questionnaire..$^{20,21}$ All subjects provided informed consent prior to their participation in this study, and the study was approved by the institutional ethics committee and conducted in accordance with the Declaration of Helsinki (2008).

\section{Experimental overview}

Subjects were tested on 2 days. On the first day they were familiarised with calf exercise and the protocol to be completed on the second day, and then they completed a series of maximum efforts for the determination of maximum voluntary force (MVC). On the second day they performed three bouts of high-intensity calf exercise during which leg blood flow, mean arterial pressure and leg vascular conductance were recorded. All tests were conducted at the same time of the day (i.e. mid morning) and same ambient temperature (i.e. $21^{\circ} \mathrm{C}$ ). Subjects did not consume alcohol and caffeine during a 24-hour period, or perform intense exercise for a 48 hour period, immediately before the testing sessions.

\section{Calf exercise}

Single-leg calf exercise was performed in an inclined position $\left(67^{\circ}\right)$ on a custom-built ergometer described previously by us. ${ }^{18}$ For both the determination of MVC and the repeated bouts of calf exercise, subjects were tilted rapidly from the supine position and then initiated contractions within $\sim 5 \mathrm{~s}$ of reaching the inclined position. The calf MVC was determined as the highest force during a series of five maximal contractions, each separated by $60 \mathrm{~s}$ of rest in the supine position. Then, on a following day, the subject rested for $20 \mathrm{~min}$ in the supine position during which resting cardiovascular measurements were made (see the 'Leg vascular conductance' section), before being tilted upright to the inclined position and commencing calf exercise soon after. ${ }^{18}$ Calf exercise consisted of intermittent and static contractions of the calf muscle ( 6 s duty cycle: $2 \mathrm{~s}$ contraction, $4 \mathrm{~s}$ relaxation) at a target force of $70 \%$ MVC. Each subject performed three calf exercise trials, separated by 20-30 min of rest in the supine position, and the duration of each exercise trial was 6 minutes.

\section{Leg vascular conductance}

Estimates of leg vascular conductance (LVC) during rest and calf exercise were based on simultaneous measurements

Table I. Physical characteristics, fasting blood-borne measurements and calf strength (MVC) in the three groups of subjects. Median and interquartile ranges are presented for weight and body mass index (BMI).

\begin{tabular}{|c|c|c|c|c|c|c|c|c|}
\hline & Age (years) & Height $(\mathrm{cm})$ & Weight (kg) & $\mathrm{BMI}\left(\mathrm{kg} \cdot \mathrm{m}^{-2}\right)$ & $\begin{array}{l}\text { Glucose } \\
(\mathrm{mmol} / \mathrm{L})\end{array}$ & $\begin{array}{l}\text { Insulin } \\
(\mathrm{mmol} / \mathrm{L})\end{array}$ & $\mathrm{HBA}_{\mathrm{Ic}}(\%)$ & $\operatorname{MVC}(\mathrm{N})$ \\
\hline $\begin{array}{l}\text { Type } 2 \\
\text { Diabetes }\end{array}$ & $49.1 \pm 5.7$ & $165 \pm 7$ & $\begin{array}{l}85.5 * \\
(74.5-117.9)\end{array}$ & $\begin{array}{l}32.5^{*} \\
(27.9-38.8)\end{array}$ & $8.1 \pm 1.7 * \dagger$ & $12.3 \pm 4.8^{*}$ & $6.8 \pm 1.0 * \dagger$ & $764 \pm 194$ \\
\hline $\begin{array}{l}\text { Heavy } \\
\text { Controls }\end{array}$ & $52.7 \pm 14.7$ & $159 \pm 4^{*}$ & $\begin{array}{l}72.7 \\
(69.1-86.1)\end{array}$ & $\begin{array}{l}29.3 \\
(29.0-31.0)^{*}\end{array}$ & $4.4 \pm 0.9$ & $11.3 \pm 4.4^{*}$ & $5.7 \pm 0.5$ & $701 \pm 194$ \\
\hline Lean Controls & $53.1 \pm 12.4$ & $172 \pm 7$ & $\begin{array}{l}64.9 \\
(63.0-71.0)\end{array}$ & $\begin{array}{l}22.6 \\
(22.0-24.0)\end{array}$ & $4.5 \pm 0.4$ & $7.6 \pm 1.3$ & $5.6 \pm 0.2$ & $766 \pm 273$ \\
\hline
\end{tabular}

* Significantly different $(p<0.05)$ from the lean group.

† Significantly different $(p<0.05)$ from the heavy control group. 
of leg blood flow and mean arterial pressure $(\mathrm{LVC}=$ leg blood flow/mean arterial pressure). Resting measurements of leg blood flow and mean arterial pressure (MAP) were made in the final three minutes of the initial $20 \mathrm{~min}$ rest period and while the subject was in the supine position. In contrast, exercise measurements of leg blood flow and MAP were made in the inclined position $\left(67^{\circ}\right)$, a position that was felt to better represent the haemodynamic conditions under which these muscles work during daily activities (e.g. walking) than the supine position. Although it would have been preferable to make both resting and exercise measurements in the inclined position, it is difficult to obtain stable estimates of leg blood flow soon after tilting to the upright position, as leg blood flow increases rapidly during tilting and can take several minutes to stabilise when in the tilted position. ${ }^{18}$ Moreover, our pilot studies ${ }^{18}$ showed that resting on the ergometer in the inclined position for several minutes often caused profound leg swelling and discomfort.

During calf exercise, leg blood flow, MAP and, thus, LVC were measured during each period of relaxation between contractions. ${ }^{18}$ For each of the three exercise trials this yielded 60 measurements of these three variables. Leg blood flow was measured during calf exercise using venous occlusion strain-gauge plethysmography, ${ }^{18}$ a technique which provides similar estimates of limb blood flow during exercise when compared with Doppler ultrasound..$^{22}$ Briefly, a thigh cuff was inflated before exercise and maintained throughout exercise at a pressure of $55 \mathrm{mmHg}$. Leg blood flow was then assessed during the 4-s relaxation periods between contractions by measuring the change in leg volume (Figure 1) using a mercury-in-Silastic strain gauge, placed around the

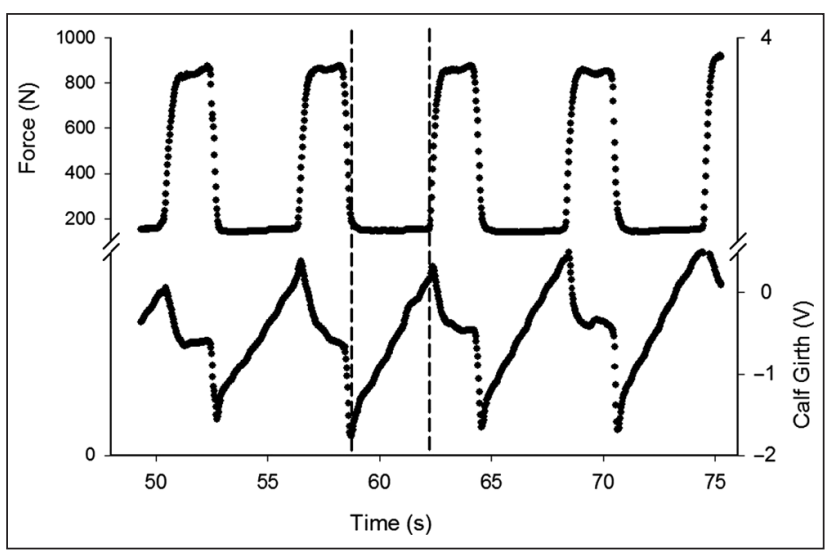

Figure I. A recording of force and the plethysmogram ('calf girth (V)') during calf exercise that illustrates the pulsatile increases in the calf girth (and volume) between contractions. The voltage change between two contractions is shown between the dashed vertical lines, and this voltage change is converted to a volume change relative to the resting limb volume (in $\mathrm{ml} 100 \mathrm{ml}^{-1}$ ) using an electronic calibration internal to the plethysmograph. Leg blood flow is then calculated from this volume change and the period over which it occurs (see Methods for further explanation). widest girth of the calf, and a plethysmograph (Hokanson EC-6, Washington, USA). The plethysmographic estimates of leg blood flow, normally expressed relative to the resting limb volume ( $\mathrm{ml} 100 \mathrm{ml}^{-1} \mathrm{~min}^{-1}$ ), were converted to millilitres per minute using an estimate of each subject's leg volume obtained from anthropometric measurements of the leg. ${ }^{23}$ These blood flow estimates were then normalised to the mean force $(\mathrm{N})$ produced immediately before its measurement $\left(\mathrm{ml}^{-1} \mathrm{~min}^{-1} \mathrm{~N}^{-1}\right)$. MAP was measured beat by beat at rest and during exercise using applanation tonometry of the radial artery (COLIN CBM7000, Japan). There were no significant differences between these tonometric MAP values and those obtained on the contralateral arm every 2 minutes using an oscillometric method (Omron M7). LVC during exercise was calculated by dividing leg blood flow by the simultaneous measurement of MAP plus the estimated hydrostatic pressure acting at the midpoint of the calf in this inclined position. ${ }^{18,24}$

\section{Dynamic response characteristics of LVC}

LVC responses (scaled to force) from the three exercise trials were averaged to yield a temporal profile of LVC based on 60 averaged estimates for each subject (an example is shown later in Figure 4). Of the 27 individual responses, 22 of them exhibited a clear biphasic pattern and the remaining five responses more closely resembled a monophasic (two heavy control subjects) or triphasic pattern (one lean control, one heavy control, one diabetic subject). On this basis, the LVC responses of all subjects were fitted using a biphasic function and the impact that deviations in measured responses from this biphasic response (in the case of five subjects) has on interpretation of the data is dealt with in the Discussion. The biphasic response was represented by the biexponential function

$$
\operatorname{LVC}(t)=a+\mathrm{A} 1\left(1-e^{-(t-\mathrm{TD} 1) / \tau 1)}\right) \mathrm{U} 1+\mathrm{A} 2\left(1-e^{-(t-\mathrm{TD} 2) / \tau 2)}\right) \mathrm{U} 2
$$

where $a$ represents LVC at $t=0$, and the amplitude, time delay and time constant of the first and second phases are represented by A1-A2, TD1-TD2 and $\tau 1-\tau 2$, respectively. The parameters $\mathrm{U} 1$ and $\mathrm{U} 2$ are conditional expressions that limit the fitting of a particular phase to the period at and beyond the time delay associated with that phase. Data that exceeded the $95 \%$ prediction intervals during an initial fit of a model were excluded, and no more than four data points were removed from the original time series of data. The models were fitted to the data using a weighted least-squares nonlinear regression procedure (LevMarqdt, TableCurve 2D, Jandel Scientific).

A graphic illustration of this biphasic model is shown in Figure 2. The magnitude of the first phase of the LVC response is defined by the parameter A1, and the temporal response of this phase is defined with respect to its onset relative to the start of exercise (i.e. the time delay TD1) and 


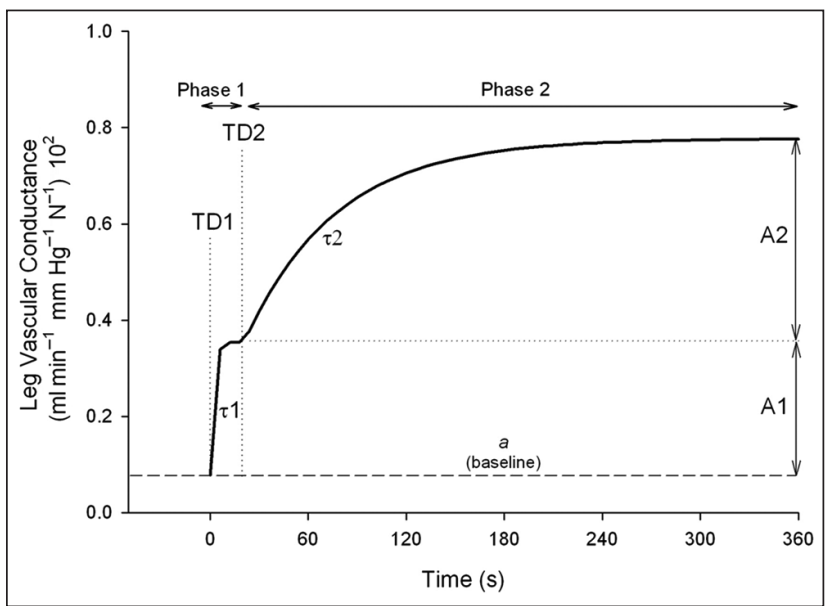

Figure 2. A graphic illustration of the biphasic model that was fitted to leg vascular conductance responses.

its rate of increase towards its asymptotic value $(\tau 1)$. This first phase is rapidly responding (small TD and $\tau$ ) and usually complete within $\sim 10 \mathrm{~s}$. The magnitude of the second phase is defined by parameter A2, its onset is delayed relative to the onset of the first phase (i.e. TD2) at $~ 20-30 \mathrm{~s}$ after exercise onset, and its rate of rise towards its asymptotic value $(\tau 2)$ is generally slower than that of the first phase. The impact that the combined effect that both phases has on the size and speed of the overall LVC response for each subject can be represented by an 'end-exercise' response (i.e. $\mathrm{LVC}$ at $t=360 \mathrm{~s}$ ) and a mean response time (MRT) calculated using the fitted biphasic function. The MRT, which represents the time to reach $\sim 63 \%$ of the overall amplitude of the response from the baseline value, was calculated as a weighted sum of the time delay and time constant of each phase:

$$
\begin{aligned}
\mathrm{MRT}= & {[\mathrm{A} 1 /(\mathrm{A} 1+\mathrm{A} 2) \cdot(\mathrm{TD} 1+\tau 1)]+} \\
& {[\mathrm{A} 2 /(\mathrm{A} 1+\mathrm{A} 2) \cdot(\mathrm{TD} 2+\tau 2)] }
\end{aligned}
$$

\section{Heart rate}

Heart rate was measured from the $R-R$ interval of singlelead (lead II) ECG at rest and every $5 \mathrm{~s}$ during each of the three calf exercise trials and averaged to yield a single time series of heart rate data for each subject. The dynamic response of heart rate during calf exercise was fitted using a monoexponential function:

$$
\text { Heart rate }(t)=a+\mathrm{A}\left(1-e^{-(t-\mathrm{TD}) / \tau}\right)
$$

where $a$ is the baseline heart rate, A is the amplitude of the exercise response, TD is the delay in rise of heart rate after exercise onset and $\tau$ is the time constant of the response. The fitting procedures were identical to that described for LVC, and because the dynamic structure of the heart rate response was not as consistent between subjects as the LVC response, a relatively simpler, monophasic function was chosen.

\section{Statistics}

Cardiovascular data at rest and during exercise were compared between the three groups of subjects using a oneway analysis of variance (ANOVA) and differences were located using Tukey's post hoc test (SigmaStat 3.5, Systat, USA). Data that were not normally distributed were analysed using a Kruskal-Wallis test and multiple comparisons were then performed using Dunn's method. The level of significance was set at $p \leq 0.05$. Results are shown as either mean \pm SD for data that were normally distributed or as median and interquartile ranges for data that were not normally distributed.

\section{Results \\ Calf exercise}

There were no significant differences in MVC between the three groups (Table 1). The submaximal force sustained during calf exercise and averaged across all contractions was not significantly different between subjects with type 2 diabetes $(66 \% \pm 4 \% \mathrm{MVC})$, heavy controls $(70 \% \pm 3 \%$ $\mathrm{MVC})$ and lean controls $(67 \% \pm 5 \% \mathrm{MVC})$.

\section{Haemodynamic measurements}

Plethysmographic measurements of resting blood flow were not different between the diabetic $(1.78 \pm 0.40 \mathrm{ml} 100$

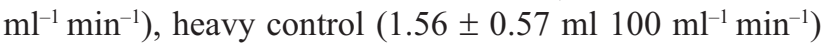
and lean control $\left(1.69 \pm 0.63 \mathrm{ml} 100 \mathrm{ml}^{-1} \mathrm{~min}^{-1}\right)$ groups. Leg blood flow was converted to units of $\mathrm{ml} \mathrm{min}^{-1}$ using anthropometric estimates of leg volume and then used to measure leg blood flow and LVC at rest and during exercise, as reported in Table 2 and Figure 3. There were no significant differences in leg blood flow, MAP or LVC measurements at rest, at $20 \mathrm{~s}$ into exercise or at the end of exercise between the three groups (Table 2). Although calf exercise evoked a significant increase in MAP in all three groups, this effect was small $(\sim 5-6 \mathrm{mmHg})$ and not different between the groups. The group-averaged responses of leg blood flow, MAP and LVC during calf exercise are shown in Figure 3. Representative LVC responses scaled to force, as well as responses predicted from the fitting of the biphasic function, are shown in Figure 4. Parameter estimates defining the biphasic response of LVC, as well as the MRT and end-exercise values calculated using these parameter estimates, are shown in Table 3 . The goodness of fit, as reflected in the adjusted $R^{2}$ value, was similar between the type 2 diabetes $(0.77 \pm 0.11)$, heavy control $(0.78 \pm 0.18)$ and lean control $(0.76 \pm 0.23)$ groups. The MRT was significantly larger $(p<0.05)$ in type 2 diabetes than the 
Table 2. Leg blood flow, mean arterial pressure and leg vascular conductance measured at rest, at $20 \mathrm{~s}$ of exercise $\left(\mathrm{Ex}_{20}\right)$ and the end of 6 minutes of exercise $\left(\mathrm{Ex}_{\text {end }}\right)$ in type 2 diabetes, heavy controls and lean controls.

\begin{tabular}{|c|c|c|c|c|c|c|c|c|c|}
\hline & \multicolumn{3}{|c|}{ Leg Blood Flow (ml min-1) } & \multicolumn{3}{|c|}{ Mean Arterial Pressure (mmHg) } & \multicolumn{3}{|c|}{$\begin{array}{l}\text { Leg Vascular Conductance } \\
\left(\mathrm{ml} \mathrm{min} \mathrm{mmHg}^{-1} \mathrm{~mm}^{-1}\right.\end{array}$} \\
\hline & Rest & $\mathrm{Ex}_{20}$ & Ex $x_{\text {end }}$ & Rest & $\mathrm{Ex}_{20}$ & Ex ${ }_{\text {end }}$ & Rest & $\mathrm{Ex}_{20}$ & Ex ${ }_{\text {end }}$ \\
\hline $\begin{array}{l}\text { Type } 2 \\
\text { Diabetes }\end{array}$ & $49 \pm 21$ & $502 \pm 322$ & $742 \pm 347$ & $93.0 \pm 7.0$ & $94.3 \pm 7.4$ & $98.0 \pm 8.7$ & $0.53 \pm 0.24$ & $3.10 \pm 1.90$ & $4.5 \pm 2.1$ \\
\hline $\begin{array}{l}\text { Heavy } \\
\text { Controls }\end{array}$ & $40 \pm 14$ & $610 \pm 158$ & $844 \pm 313$ & $91.4 \pm 11.3$ & $92.0 \pm 11.9$ & $96.8 \pm 11.2$ & $0.45 \pm 0.20$ & $4.01 \pm 1.18$ & $5.3 \pm 2.0$ \\
\hline $\begin{array}{l}\text { Lean } \\
\text { Controls }\end{array}$ & $39 \pm 15$ & $664 \pm 331$ & $909 \pm 584$ & $93.1 \pm 10.8$ & $93.6 \pm 13.1$ & $98.0 \pm 14.4$ & $0.43 \pm 0.16$ & $4.19 \pm 2.16$ & $5.6 \pm 3.6$ \\
\hline
\end{tabular}

Table 3. Dynamic response characteristics of leg vascular conductance (LVC) during calf exercise in type 2 diabetes, heavy controls and lean controls. Amplitudes (' $a$ ', 'Al', 'A2' and 'end-exercise LVC') are expressed in $\mathrm{ml} \mathrm{min}^{-1} \mathrm{mmHg}^{-1} \mathrm{~N}^{-1}$, and timebased parameters ('TDI', $\tau$ I,TD2, $\tau 2$ and MRT) are expressed in seconds. See Methods and Figure 2 for further description. Mean response time (MRT) data were not normally distributed and are presented as median and interquartile range.

\begin{tabular}{|c|c|c|c|c|c|c|c|c|c|}
\hline & \multirow{2}{*}{$\begin{array}{l}\text { Baseline } \\
a\end{array}$} & \multicolumn{3}{|l|}{ Phase I } & \multicolumn{3}{|l|}{ Phase 2} & \multirow[b]{2}{*}{ MRT } & \multirow[b]{2}{*}{$\begin{array}{l}\text { End-exercise } \\
\text { LVC }\end{array}$} \\
\hline & & $\mathrm{Al}$ & TDI & $\tau l$ & $\mathrm{~A} 2$ & TD2 & $\tau 2$ & & \\
\hline $\begin{array}{l}\text { Type } 2 \\
\text { Diabetes }\end{array}$ & $0.09 \pm 0.04$ & $0.54 \pm 0.28$ & $0.0 \pm 0.0$ & $3.4 \pm 2.2$ & $0.35 \pm 0.20$ & $27.1 \pm 16.0$ & $66.4 \pm 29.2^{*}$ & $\begin{array}{l}30.7 \\
(24.6-46.5)^{*}\end{array}$ & $0.96 \pm 0.35$ \\
\hline $\begin{array}{l}\text { Heavy } \\
\text { Controls }\end{array}$ & $0.09 \pm 0.03$ & $0.65 \pm 0.22$ & $1.3 \pm 1.6$ & $3.1 \pm 3.3$ & $0.36 \pm 0.20$ & $23.2 \pm 7.1$ & $22.2 \pm 13.4$ & $\begin{array}{l}16.3 \\
(4.3-23.2)\end{array}$ & $1.04 \pm 0.35$ \\
\hline Lean Controls & $0.07 \pm 0.05$ & $0.69 \pm 0.26$ & $0.5 \pm 1.4$ & $3.5 \pm 2.3$ & $0.37 \pm 0.16$ & $27.6 \pm 15.1$ & $21.8 \pm 9.3$ & $\begin{array}{l}18.4 \\
(13.7-19.3)\end{array}$ & $1.10 \pm 0.37$ \\
\hline
\end{tabular}

* Significantly different $(p<0.05)$ from the other groups.

control groups; whereas the end-exercise values were similar between the three groups. The time constant of the second phase $(\tau 2)$ was also significantly larger in type 2 diabetes than controls. None of the remaining parameters were significantly different between the groups, although the parameter TD1 tended to be different between the groups (ANOVA, $p=0.06$ ).

\section{Heart rate}

The baseline or resting heart rate (parameter $a$ ) immediately before calf exercise was not significantly different between the type 2 diabetes (67 $\pm 11 \mathrm{bpm})$, heavy control $(67 \pm 8 \mathrm{bpm})$ and lean control $(61 \pm 8 \mathrm{bpm})$ groups. When comparing the dynamic response characteristics of heart rate between these three groups (type 2 diabetes versus heavy versus lean), there were no significant differences in the amplitude (parameter A: $17.3 \pm 4.4$ versus $14.5 \pm$ 4.7 versus $14.7 \pm 8.4 \mathrm{bpm}$ ), time delay (parameter TD: $0.2 \pm 0.6$ versus $0.2 \pm 0.3$ versus $2.2 \pm 3.5 \mathrm{~s}$ ) or time constant (parameter $\tau: 6.7 \pm 5.1$ versus $11.8 \pm 17.9$ versus $14.2 \pm 16 \mathrm{~s})$.

\section{Discussion}

A major finding of the present study is that, compared with both lean and heavy controls, the response of LVC and blood flow during calf exercise was profoundly slowed in type 2 diabetes patients. In contrast, the response of MAP during exercise was not different between these three groups. This slowing of the hyperaemic response, evident in a significantly larger MRT for LVC, can be attributed entirely to the slower rate of increase (i.e. larger time constant) of the second phase of the hyperaemic response; whereas the first phase was unaffected by type 2 diabetes. The similar LVC and blood flow responses between lean and heavy controls suggests that obesity per se is not responsible for the impaired hyperaemic response in type 2 diabetes.

\section{Dynamic response characteristics of leg vascular conductance}

In the presence of similar MAP responses between the three groups, the slower leg blood flow response in type 2 diabetes can be attributed to a slower response of LVC (Figure 3) 


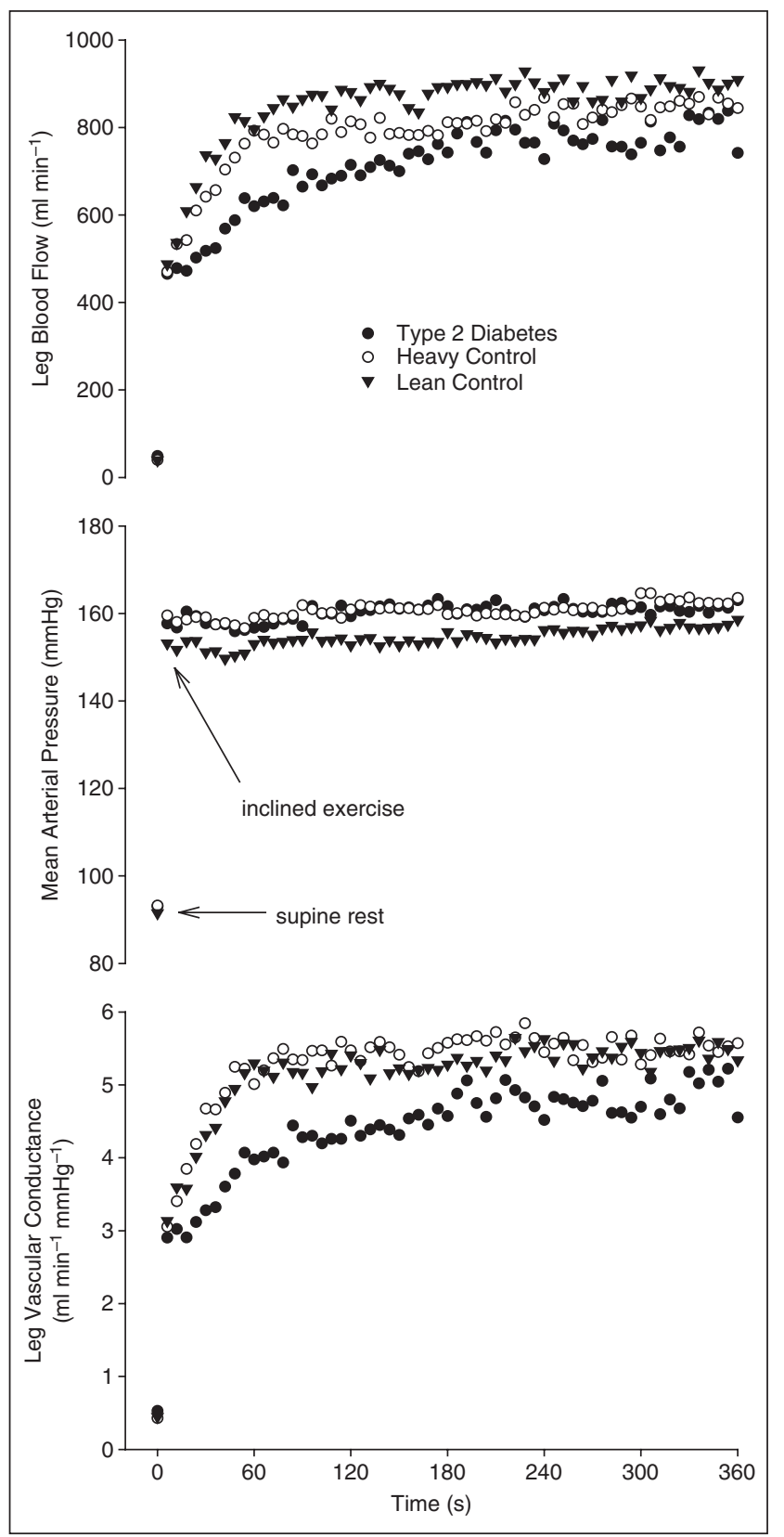

Figure 3. Group averaged responses of leg blood flow, mean arterial pressure and leg vascular conductance during calf exercise. 'Mean arterial pressure' in this figure is the local arterial pressure estimated to act at the popliteal fossa, and so the abrupt increase in this response after $t=0 \mathrm{~s}$ represents the arterial pressure measured in the forearm plus the hydrostatic pressure that acts at the knee when the subject is rapidly tilted to the inclined position.

and, thus, vasodilation in the contracting skeletal muscle. A high frequency of measurements of LVC during exercise combined with empirical modelling of this dynamic response enables the dynamic structure of these phases to be resolved. ${ }^{14}$ The dynamic response of each phase is assumed to be an exponential process defined by a set of

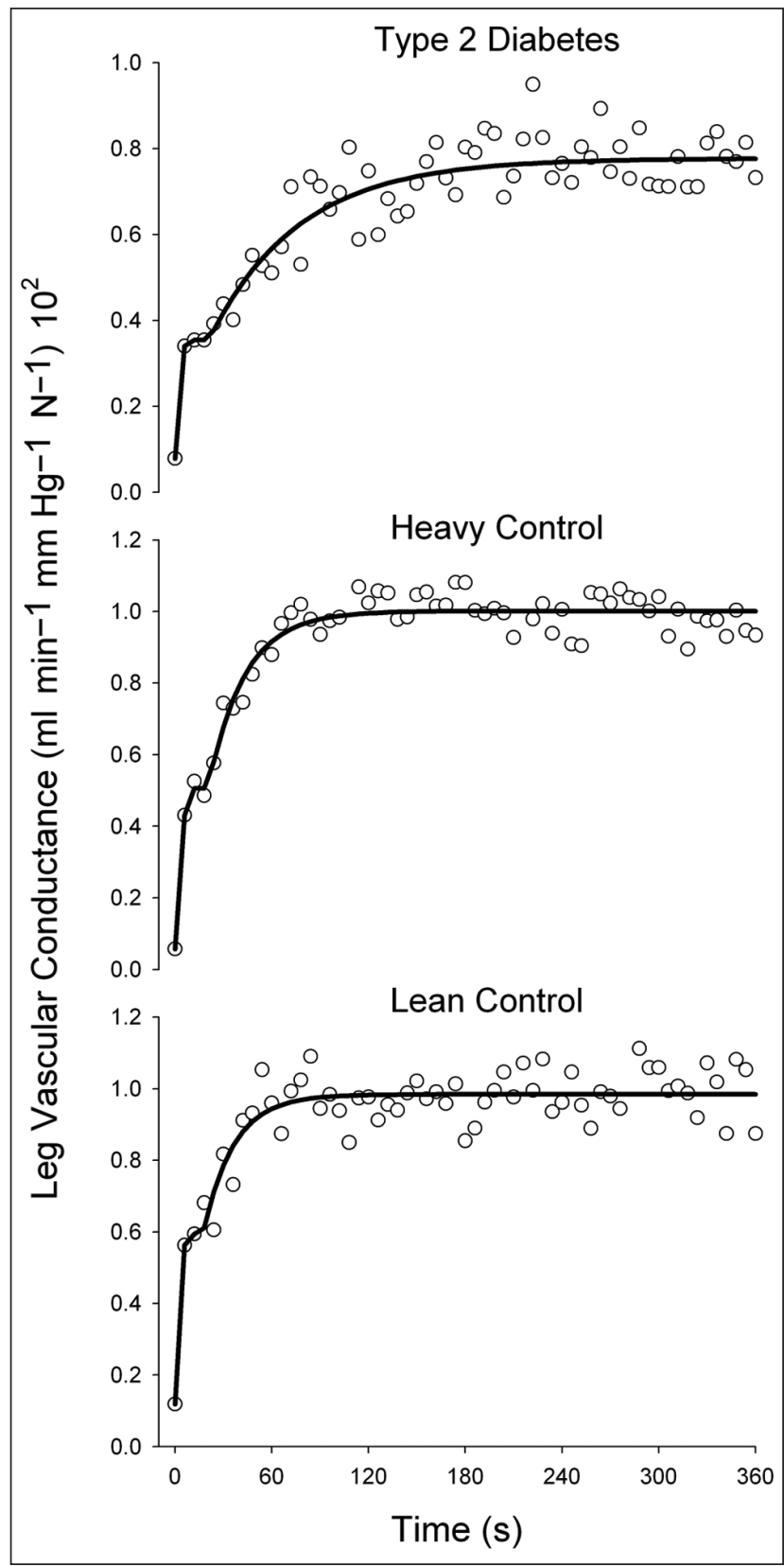

Figure 4. Leg vascular conductance (LVC) responses (open circles) during calf exercise in an individual with type 2 diabetes, a heavy control and a lean control. The continuous lines of best fit illustrate the biphasic response of LVC. Note the relatively slow response of the second hyperaemic phase in the diabetic subject.

parameters that include the amplitude, time constant and time delay. It has been suggested that each phase and the parameters which define its structure potentially represent a distinct set of underlying control mechanisms involved in vascular control. ${ }^{13}$ In the present study, LVC was modelled using a biexponential function on the basis that a biphasic response was more apparent (22/27 subjects) than either a monophasic or triphasic response. This is consistent with 
the biphasic response of arteriolar vasodilation to muscle stimulation observed in the hamster cremaster muscle preparation, ${ }^{25,26}$ as well as the biphasic response of forearm blood flow during moderate handgrip exercise. ${ }^{17}$ However, as is apparent in forearm vascular conductance responses to handgrip exercise,${ }^{17}$ not all responses can be characterised by the same number of phases. In the present study, two subjects (both heavy controls) exhibited a monophasic response and, thus, the estimated amplitude of the second phase of these responses was zero, whereas three subjects (one from each group) exhibited a triphasic response, and this would result in an overestimate of the amplitude and time constants of the second phase for these subjects. However, neither of these observations can account for the longer time constant of the second phase of the hyperaemic response in the diabetic group compared with the lean or heavy control groups.

\section{Mechanisms of vascular control during exercise}

A wide range of mechanisms probably contributes to the biphasic control of vascular conductance in contracting human muscles, although the precise contribution of any one mechanism to either phase is not yet clear. The first phase of vasodilation is initiated in response to the first contraction and is fully expressed within $\sim 10-20 \mathrm{s.}^{17}$ Likely mechanisms involved in this initial phase include $\mathrm{K}^{+}$release into the interstitium ${ }^{27}$ and mechanical deformation of resistance vessels, ${ }^{28}$ as well as acetylcholine release from the motor nerves ${ }^{29}$ although there is some uncertainty regarding its effectiveness in contracting human skeletal muscle. ${ }^{30,31} \mathrm{In}$ addition, the increase in the perfusion pressure under the permissive influence of the 'muscle pump" ${ }^{32}$ will increase limb blood flow beyond that supported by vasodilation, and it will do so in response to the first contraction and particularly when the limb is well below the level of the heart. ${ }^{18}$

The second phase of vasodilation is initiated at $\sim 20-30 \mathrm{~s}$ after exercise onset (Table 2), ${ }^{17}$ and it has been suggested that the second phase is a flow-mediated, endotheliumdependent phase ${ }^{13}$ that is perhaps linked causally to the decline in muscle $\mathrm{PO}_{2}{ }^{25}$ It is likely that adenosine, a potent vasodilator in human skeletal muscle, ${ }^{33}$ is linked to the decline in muscle $\mathrm{PO}_{2}$ and contributes to this second phase, ${ }^{25}$ despite the uncertainty about its time course of accumulation in the interstitial fluid during the first phase of the hyperaemic response. ${ }^{34}$ Both nitric oxide and prostaglandins may be involved in this vascular action of adenosine or contribute independently to the exercise hyperaemic response, ${ }^{35,36}$ although the inhibition of nitric oxide synthesis has little effect on the rise in muscle blood flow during exercise. ${ }^{31,37}$ Both the classic autoregulation (Bayliss mechanism) response and muscle sympathetic nerve activation have the potential to modulate both biphasic responses; but their contributions to the dynamic response characteristics have not, to the best of the authors' knowledge, been established.

\section{Mechanisms of impaired vascular control in diabetes}

The slowed hyperaemic response observed in the present study combined with the more rapid decline in muscle microvascular $\mathrm{PO}_{2}$ and deoxygenated haemoglobin ${ }^{12,38}$ in type 2 diabetes suggests that the speed of the vasodilatory response to a metabolic stimulus is impaired in this disease. In contrast, neither the end-exercise value or phasic amplitudes of LVC were significantly affected by type 2 diabetes (Table 2), suggesting that the capacity to vasodilate under exercise conditions that evoke near-maximal blood flows ${ }^{18}$ remains intact. However, the phase 1 amplitude and endexercise value for LVC was $15-20 \%$ lower in the diabetic group and, although this difference was not significant, the large between-subject variation in responses might have obscured an important physiological difference which warrants further investigation. Nevertheless, given that the initial hyperaemic response (phase 1) was not significantly affected by type 2 diabetes, the slowed second phase response is probably not due to a lower preceding flow stimulus and above-mentioned mechanisms that underlie it and is perhaps more likely explained by the failure of endothelial-mediated vasodilation to amplify the early rise in vascular conductance.

There are a number of potential mechanisms that underlie vascular dysfunction in type 2 diabetes ${ }^{39}$ Of particular relevance to the present findings is evidence that type 2 diabetes or hyperglycaemia impairs flow-mediated and endothelial-dependent control of vascular resistance in the human forearm. ${ }^{11,}$ 40-41 Flow-mediated and endothelialdependent control mechanisms are thought to be central to the time-dependent propagation of vasodilation from distal to more proximal resistance vessels, a critical process in controlling the hyperaemic response during muscle contractions. ${ }^{42}$ This process depends on the gap junction intercellular communication between endothelial cells and smooth muscle, ${ }^{42}$ a process that is affected by high glucose concentrations. ${ }^{39}$ It is tempting to speculate that hyperglycaemiainduced disruption of this cell-to-cell mediated control over the vascular response during exercise contributes to the slowing of the second phase of the hyperaemic response in type 2 diabetes.

To some extent the vascular mechanisms which impair the muscle hyperaemic response in type 2 diabetes might depend on the exercise model used and/or muscles studied. That the amplitudes of the LVC response during high-intensity calf exercise were unaffected by type 2 diabetes is consistent with the maximal vasodilation in the hindlimb of the streptozotocin-induced diabetic rat being similar to control animals. ${ }^{43}$ However, they contrast with the lower steady-state values of limb blood flow during lower intensity cycling ${ }^{11}$ and knee 
extension exercise. ${ }^{2}$ We can only speculate on the reasons for this discrepancy and which might include both the intensity of exercise (moderate versus 'maximal'), the muscles studied (quadriceps versus calf) and the potential influence of muscle atrophy (if present) on vascular conductance. In addition, the influence of sympathetically mediated vasoconstriction in muscle on exercise hyperaemia in type 2 diabetes warrants further study, since it is increased at rest in an insulin-resistant state ${ }^{44}$ and has been proposed as a possible candidate for the age-related blunting of the hyperaemic response to exercise involving the quadriceps muscles. ${ }^{45}$ The pharmacotherapy used by the present diabetic group, which includes metformin, statins and ACE inhibitors, is unlikely to account for the vascular dysfunction observed in the present study given that these drugs generally enhance vascular function.

It has been suggested that cardiac dysfunction, a major complication of type 2 diabetes, ${ }^{7}$ might contribute to altered blood flow or $\dot{V}_{2}$ responses in type 2 diabetes. ${ }^{1-4}$ This, however, seems an unlikely mechanism in the present study given the following: (1) LVC reflects vasodilation in the contracting skeletal muscle; (2) differences in the leg blood flow response is entirely a function of LVC given that the pressor responses were similar between the three groups; (3) the small but significant rise in MAP in the subjects with type 2 diabetes demonstrates that cardiac function is sufficient to maintain blood pressure in the presence of a progressive decline in leg vascular resistance; and (4) there was no difference in the dynamic response of heart rate during calf exercise between the three groups. The common interpretation that a lowered cardiac output or slowed heart rate 'kinetics' observed during exercise in type 2 diabetes reflects cardiac dysfunction ${ }^{1-4}$ is, in the absence of simultaneous arterial pressure measurements, tenuous. An alternative explanation for such cardiac responses is that they reflect vascular dysfunction and altered responses of limb blood flow.

\section{Relevance to $\mathrm{VO}_{2}$ and exercise tolerance}

Like limb blood flow and vascular conductance, $\dot{V}_{2}$ increases in a biphasic manner during moderate exercise. Type 2 diabetes slows the second of these two phases of $\dot{V}_{2}, 3,6$ and we have observed the same effect on $\dot{V}_{2}$ kinetics in a sample of women that included many of those who participated in the present study. ${ }^{46}$ Given the close temporal alignment between the muscle blood flow and $\dot{V}_{2}$ responses, ${ }^{47}$ the present findings suggest that this slowing is, at least in part, due to a slowing of the second phase of hyperaemia. Impeding $\dot{V}_{\mathrm{O}_{2}}$ after the onset of exercise exaggerates the fall in muscle $\mathrm{PCr}$ and $\mathrm{pH}$, increase in $\mathrm{P}_{\mathrm{i}}$ and loss of force production. ${ }^{48-51}$ Therefore, it is likely that the slowing of the hyperaemic response (phase 2) contributes directly to the abnormal metabolic responses in contracting muscle and the loss of exercise tolerance in type 2 diabetes. ${ }^{1-4,6,46}$

\section{Limitations}

Although the resting ankle-brachial pressure index is a criterion measure of peripheral arterial disease, it can be inaccurate in diabetic subjects because of the presence of arterial calcification and the associated stiffening. Angiography or Doppler ultrasound was not performed in this study and so we cannot rule out the presence of clinically significant macrovascular disease and its potential influence on the slowed hyperaemic response in the diabetic subjects. Both pre- and post-menopausal women were studied and menopause appears to reduce endothelial-dependent vasodilation. ${ }^{52}$ However, this is unlikely to have introduced bias in the results given that the distribution of pre- and postmenopausal women was similar in the three groups. The accuracy of plethysmographic measurements of leg blood flow has been questioned. ${ }^{53,54}$ However, recent work from one of our laboratories shows very close agreement between plethysmographic and Doppler ultrasound estimates of leg blood flow during calf exercise. ${ }^{55}$

\section{Conclusion}

In conclusion, the present findings demonstrate a slowing of the hyperaemic response during calf exercise in type 2 diabetes that is attributed to the second phase of this response. This lays a foundation for further human research into the mechanisms underlying this effect and their impact on metabolic control and exercise tolerance in type 2 diabetes.

\section{Funding}

This research received no specific grant from any funding agency in the public, commercial, or not-for-profit sectors.

\section{Conflict of interest statement}

The authors declare that they have no conflicts of interest.

\section{References}

1. Baldi JC, Aoina JL, Oxenham HC, Bagg W and Doughty $\mathrm{RN}$. Reduced exercise arteriovenous $\mathrm{O}_{2}$ difference in type 2 diabetes. J Appl Physiol 2003; 94: 1033-1038.

2. Lalande S, Gusso S, Hofman PL and Baldi JC. Reduced leg blood flow during submaximal exercise in type 2 diabetes. Med Sci Sports Exerc 2008; 40: 612-617.

3. Regensteiner JG, Bauer TA, Reusch JEB, et al. Abnormal oxygen uptake kinetic responses in women with type II diabetes mellitus. J Appl Physiol 1998; 85: 310-317.

4. Regensteiner JG, Sippel J, McFarling ET, Wolfel EE and Hiatt WR. Effects of non-insulin dependent diabetes on oxygen consumption during treadmill exercise. Med Sci Sports Exerc 1995; 27: 661-667.

5. Wei M, Gibbons LW, Kampert JB, Nichaman MZ and Blair SN. Low cardiorespiratory fitness and physical inactivity as predictors of mortality in men with type 2 diabetes. Ann Intern Med. 2000; 132: 605-611. 
6. Bauer TA, Brass EP, Barstow TJ and Hiatt WR. Skeletal muscle $\mathrm{StO}_{2}$ kinetics are slowed during low work rate calf exercise in peripheral arterial disease. Eur J Appl Physiol 2007; 100: 143-151.

7. Scheuermann-Freestone M, Madsen PL, Manners D, et al. Abnormal cardiac and skeletal muscle energy metabolism in patients with type 2 diabetes. Circulation 2003; 107: 3040-3046.

8. Hughson RL, Tschakovsky ME and Houston ME. Regulation of oxygen consumption at the onset of exercise. Exerc Sport Sci Rev 2001; 29: 129-133.

9. Hughson RL. Regulation of $\mathrm{VO}_{2}$ on-kinetics by $\mathrm{O}_{2}$ delivery. In Jones AM and Poole DC (Eds), Oxygen Uptake Kinetics in Sport, Exercise and Medicine. New York: Routledge, 2005, pp. 185-211.

10. Poole DC, Barstow TJ, McDonough P and Jones AM. Control of oxygen uptake during exercise. Med Sci Sports Exerc 2008; 40: 462-474.

11. Kingwell BA, Formosa M, Muhlmann M, Bradley SJ and McConnell GK. Type 2 diabetic individuals have impaired leg blood flow responses to exercise. Diabetes Care 2003; 26: 899-904.

12. Behnke BJ, Kindig CA, McDonough P, Poole DC and Sexton WL. Dynamics of microvascular oxygen pressure during rest-contraction transition in skeletal muscle of diabetic rats. Am J Physiol-Heart Circul Physiol 2002; 283: H926-H932.

13. Tschakovsky ME, Saunders NR, Webb KA and O'Donnell DE. Muscle blood flow dynamics at exercise onset: Do the limbs differ? Med Sci Sports Exerc 2006; 38: 1811-1818.

14. Lamarra N. Variables, constants, and parameters: clarifying the system structure. Med Sci Sports Exerc 1990; 22: 88-95.

15. Hughson RL. Exploring cardiorespiratory control mechanisms through gas exchange dynamics. Med Sci Sports Exerc 1990; 22: 72-79.

16. Whipp BJ. Rate constant for the kinetics of oxygen uptake during light exercise. J Appl Physiol 1971; 30: 261-263.

17. Saunders NR, Pyke KE and Tschakovsky ME. Dynamic response characteristics of local muscle blood flow regulatory mechanisms in human forearm exercise. J Appl Physiol 2005; 98: 1286-1296.

18. Egana M and Green S. Effect of body tilt on calf muscle performance and blood flow in humans. J Appl Physiol 2005; 98: 2249-2258.

19. Green S. Haemodynamic limitations and exercise performance in peripheral arterial disease. Clin Physiol Functional Imag 2002; 22: 81-91.

20. Hiatt WR, Hirst A, Regensteiner JG and Brass EP. Assessment of patients with peripheral arterial disease: review of approaches and development of recommendations for therapeutic trials. Circulation 1995; 92: 614-621.

21. Regensteiner JG, Steiner JF and Hiatt WR. Exercise training improves functional status in patients with peripheral arterial disease. J Vasc Surg 1996; 23: 104-115.

22. Longhurst J, Capone RJ, Mason DT and Zelis R. Comparison of blood flow measured by plethysmograph and flowmeter during steady state forearm exercise. Circulation 1974; 49: 535-40.
23. Clarys JP and Marfell-Jones MJ. Anthropometric prediction of component tissue masses in the minor limb segments of the human body. Hum Biol 1986; 58: 761-769.

24. Egana M, Green S, Garrigan EJ and Warmington S. Effect of posture on high-intensity constant-load cycling performance in men and women. Eur J Appl Physiol 2006; 96: 1-9.

25. Gorczynski RJ and Duling BR. Role of oxygen in arteriolar functional vasodilation in hamster striated muscle. Am J Physiol 1978; 235: H505-H515.

26. van Teeffelen JWGE and Segal SS. Effect of motor unit recruitment on functional vasodilatation in hamster retractor muscle. J Physiol 2000; 524: 267-278.

27. Armstrong ML, Dua AK and Murrant CL. Potassium initiates vasodilatation induced by a single skeletal muscle contraction in hamster cremaster muscle. $J$ Physiol 2007; 581: 841-52.

28. Clifford PS. Skeletal muscle vasodilatation at the onset of exercise. J Physiol 2007; 583: 825-833.

29. VanTeeffelen J and Segal SS. Rapid dilation of arterioles with single contraction of hamster skeletal muscle. Am J Physiol-Heart Circul Physiol 2006; 290: H119-H127.

30. Hellsten Y, Krustrup P, Iaia FM, Secher NH and Bangsbo J. Partial neuromuscular blockade in humans enhances muscle blood flow during exercise independently of muscle oxygen uptake and acetylcholine receptor blockade. Am J Physiol 2009; 296: R1106-R1112.

31. Shoemaker JK, Halliwill JR, Hughson RL and Joyner MJ. Contributions of acetylcholine and nitric oxide to forearm blood flow at exercise onset and recovery. Am J PhysiolHeart Circul Physiol 1997; 42: H2388-H2395.

32. Sheriff D. Point: The muscle pump raises muscle blood flow during locomotion. J Appl Physiol 2005; 99: 371-372.

33. Marshall JM. The roles of adenosine and related substances in exercise hyperaemia. J Physiol. 2007; 583: 835-845.

34. Hellsten Y, Maclean D, Radegran G, Saltin B and Bangsbo $\mathrm{J}$. Adenosine concentrations in the interstitium of resting and contracting human skeletal muscle. Circulation 1998; 98: 6-8.

35. Mortensen SP, Gonzalez-Alonso J, Bune LT, Saltin B, Pilegaard H and Hellsten Y. ATP-induced vasodilation and purinergic receptors in the human leg: roles of nitric oxide, prostaglandins, and adenosine. Am J Physiol 2009; 296: R1140-R1148.

36. Mortensen SP, Nyberg M, Thaning P, Saltin B and Hellsten Y. Adenosine contributes to blood flow regulation in the exercising human leg by increasing prostaglandin and nitric oxide formation. Hypertension 2009; 53: 993-U177.

37. Radegran G and Saltin B. Nitric oxide in the regulation of vasomotor tone in human skeletal muscle. Am J PhysiolHeart Circul Physiol 1999; 276: H1951-H60.

38. Bauer TA, Reusch JEB, Levi $M$ and Regensteiner JG. Skeletal muscle deoxygenation after the onset of moderate exercise suggests slowed microvascular blood flow kinetics in type 2 diabetes. Diabetes Care 2007; 30: 2880-2885.

39. Figueroa XF and Duling BR. Gap junctions in the control of vascular function. Antioxidants Redox Signal 2009; 11: 251-266.

40. De Filippis E, Cusi K, Ocampo G, et al. Exercise-induced improvement in vasodilatory function accompanies increased 
insulin sensitivity in obesity and type 2 diabetes mellitus. J Clin Endocrinol Metab 2006; 91: 4903-4910.

41. Williams SB, Goldfine AB, Timimi FK, et al. Acute hyperglycemia attenuates endothelium-dependent vasodilation in humans in vivo. Circulation 1998; 97: 1695-1701.

42. Segal SS. Regulation of blood flow in the microcirculation. Microcirculation 2005; 12: 33-45.

43. Sexton WL. Skeletal muscle vascular transport capacity in diabetic rats. Diabetes 1994; 43: 225-231.

44. Straznicky N, Lambert GW, Masuo K, et al. Blunted sympathetic neural response to oral glucose in obese subjects with the insulin-resistant metabolic syndrome. Am J Clin Nutr $2009 ; 89$.

45. Lawrenson L, Poole JG, Kim J, Brown C, Patel P and Richardson RS. Vascular and metabolic response to isolated small muscle mass exercise: effect of age. Am J Physiol 2003; 285: H1023-H1031.

46. MacAnaney O, Malone J, Warmington S, O'Shea D, Green S and Egana M. Cardiac output responses are not related to the slowed oxygen uptake kinetics in type 2 diabetes. Med Sci Sports Exerc, in press.

47. MacDonald MJ, Shoemaker JK, Tschakovsky ME and Hughson RL. Alveolar oxygen uptake and femoral artery blood flow dynamics in upright and supine leg exercise in humans. J Appl Physiol 1998; 85: 1622-1628.
48. Hogan MC, Arthur PG, Bebout DE, Hochachka PW and Wagner PD. Role of $\mathrm{O}_{2}$ in regulating tissue respiration in $\operatorname{dog}$ muscle working in situ. J Appl Physiol 1992; 73: 728-736.

49. Hogan MC, Gladden LB, Grassi B, Stary CM and Samaja M. Bioenergetics of contracting skeletal muscle after partial reduction of blood flow. J Appl Physiol 1998; 84: 1882-1888.

50. Hogan MC, Richardson RS and Kurdak SS. Initial fall in skeletal muscle force development during ischemia is related to oxygen availability. J Appl Physiol 1994; 77: 2380-2384.

51. Timmons J, Gustafsson T, Sundberg E, Jansson E and Greenhaff P. Substrate availability limits human skeletal muscle oxidative ATP regeneration at the onset of ischaemic exercise. J Clin Invest 1998; 101: 79-85.

52. Taddei S, Virdis A, Ghiadoni L, et al. Menopause is associated with endothelial dysfunction in women. Hypertension 1996; 28: 576-582.

53. Radegran G. Limb and skeletal muscle blood flow measurements at rest and during exercise in human subjects. Proc Nutr Soc 1999; 58: 887-98.

54. Saltin B. Exercise hyperaemia: magnitude and aspects on regulation in humans. J Physiol 2007; 583: 819-823.

55. Green S, Thorp R, Reeder E, Donnelly J and Fordy G. Venous occlusion plethysmography versus Doppler ultrasound in the assessment of leg blood flow during calf exercise. Eur J Appl Physiol, in review. 